\title{
Dramaturgia cabo-verdiana A “crioulização" como adaptação de textos dramáticos universais ao contexto do arquipélago
}

\section{Micaela Barbosa}

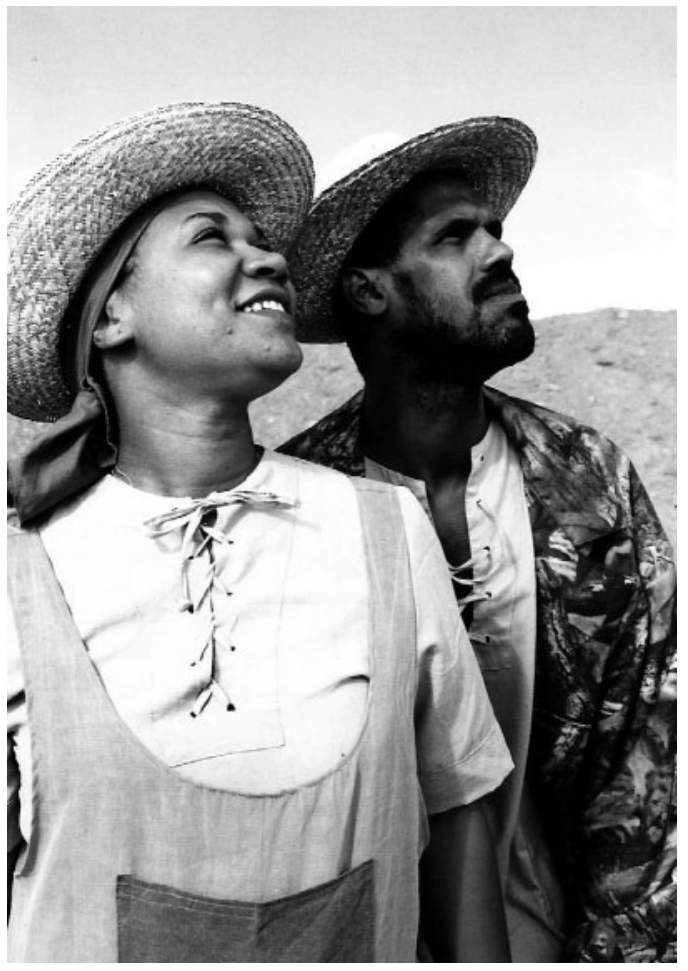

Em Cabo Verde, desde 1997 que se assiste, na dramaturgia, a um trabalho peculiar realizado pelo Grupo de Teatro do Centro Cultural Português do Mindelo (GTCCPM) / Instituto Camões, que o seu responsável, João Branco, apelida de "crioulização", consistindo na adaptação, tradução, assimilação, "a partir de ...", ou seja, variados modos de alterar um texto dramático e o ligar a Cabo Verde: "...é uma assimilação. É pegar num corpo que é estranho e torná-lo um corpo próprio, não só um corpo cultural, mas também social (...) para fazer sentido enquanto objecto artístico cabo-verdiano."

0 que o autor procura é atribuir à obra ligações com o contexto cultural e social de Cabo Verde, provocando uma identificação dos espectadores, quer seja através da exploração de temáticas que constroem a identidade caboverdiana, quer através da adaptação do espaço e tempo dramático: "A identidade do Mindelo está no meu trabalho?

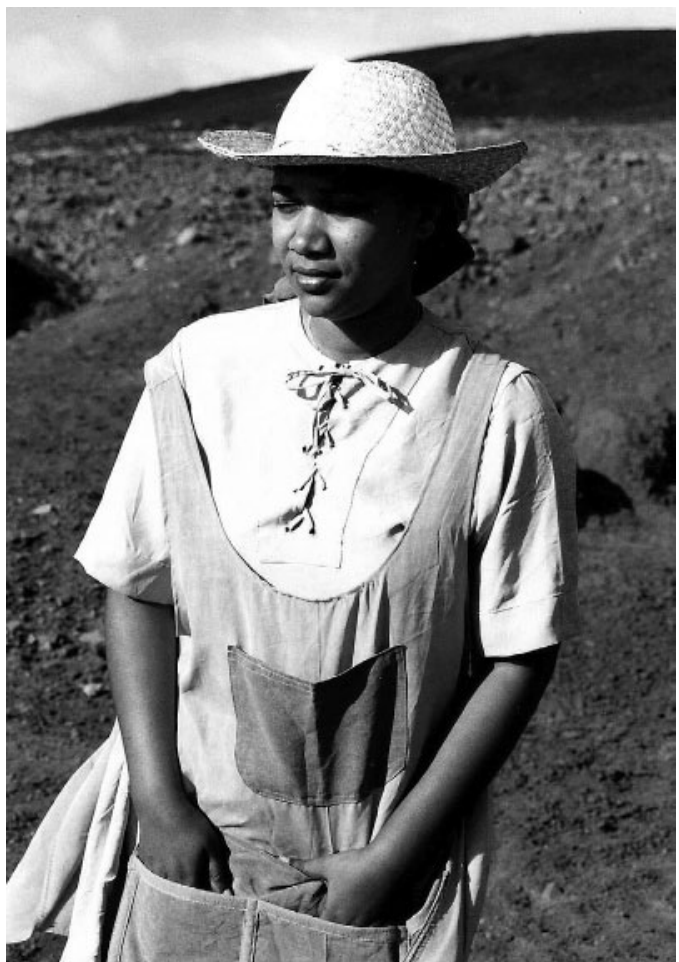

$\dot{A}$ espera da chuva, escrita e enc. João Branco, Grupo de Teatro do Centro Cultural Português do Mindelo, 2002 (< Maria da Luz Faria e Jorge Spenser; $>$ Maria da Luz Faria), fot. João Branco.

1 João Branco, Jornal de Noticias de 6 de Maio de 1999

2 João Branco entrevistado por Micaela Barbosa em Abril de 2006

Vamos cometer uma "heresia" que em Cabo Verde tem todo o sentido: Godot vai ser identificado, será a chuva!

Respeito o teatro que não apresenta ligação ao referencial espacial, mas prefiro a outra vertente." ${ }^{.3}$, ou ainda, na tradução para o crioulo, como afirma:

\begin{abstract}
Esta é uma componente muito importante no nosso trabalho teatral talvez até aquela que é mais visivel. A ideia nunca foi a encenação dos clássicos teatrais num contexto estranho à nossa realidade, mas, antes pelo contrário, o aproveitamento desses textos empolgantes, adaptando-os à nossa realidade, em peças que na maioria dos casos são faladas em português e crioulo, bem à imagem do meio mindelense. (Branco 2003: 288)
\end{abstract}

João Branco não se limita a traduzir para o crioulo, faz uma tradução cultural:

Digamos que as palavras originais são quase só um pretexto ou uma motivação para a abordagem de determinadas temáticas locais, e

\section{Ibidem.}

Micaela Barbosa é licenciada em Estudos Teatrais pela e Mestre em Texto Dramático pela Faculdade de Letras da Universidade do Porto com a tese intitulada A ldentidade Caboverdiana na Dramaturgia: Tradição africana e cânone ocidental no Korda Kaoberdi e Grupo de Mindelo. Universidade de Évora Teatro do CCP do 
que uma vez concretizada a transformação do texto e a sua apresentação pública enquanto obra cénica, passamos a estar presentes diante de uma outra forma (...) de uma peça de teatro genuinamente cabo-verdiana. (Branco 2004: 340)

Este trabalho vai para além de tradução de um texto. Quando falamos em tradução de uma obra de teatro, temos que ter em conta a especificidade deste género literário: é um texto que só se torna eficaz aquando da sua representação. Branco traduz o texto tendo em vista um produto para o palco, pelo que é um trabalho feito in fieri durante os ensaios, modificados e actualizados até ao dia da estreia. 0 público terá uma grande influência nas traduções. As réplicas constroem-se tendo em conta o contexto de chegada - o público - em oposição ao texto escrito, construindo-se assim uma obra nova, original, um novo texto. Quando Branco fala em "crioulização" como adaptação ou versão, tem já nas suas premissas a ideia de texto para levar ao palco, ou seja, é uma tradução para o espectáculo, em oposição à tradução literária. Usando palavras de Aaltonen:

Adaptação como uma estratégia de tradução que se desvia do texto de origem (...) a escrita de um novo texto em torno das temáticas do texto fonte. Uma adaptação pode reactualizar o texto de partida apenas pela tradução de algumas partes, retirando ou alterando outras. (Aaltonen 2007: 270)

Isto vem ao encontro do que Branco procura, que é "re-actualizar" a peça no contexto cabo-verdiano. E a própria crioulização, entendida como uma tradução do ponto de vista do encenador, preza, como nos diz Bassnett, a eficácia cénica, nem que tenha que alterar o texto do ponto de vista linguístico e estilístico (1991: 122).

João Branco traduz as suas peças para crioulo, segundo ele, devido à sua eficácia enquanto língua da oralidade:
Para tornar esses autores, como Brecht, Lorca ou Shakespeare mais nossos, há uma coisa fundamental que tento fazer, um teatro próximo das pessoas, que é a questão da lingua: tanto com Lorca como com Shakespeare o texto original foi traduzido e adaptado para o crioulo. Na minha opinião, penso que devemos ter essa "ousadia" de poder mexer nesses textos. (Branco 2000: 48)

A tradução para o crioulo é, então, a primeira característica da crioulização, que coloca logo à partida o texto dentro da realidade cabo-verdiana, ou seja, o uso do crioulo cria por si uma marca identitária. 0 próprio termo crioulização, que João Branco assumiu para o seu trabalho, passa, não só, mas muito, pela tradução linguistica:

Quando uma obra é universal, quer dizer que ela é um pouco nossa também. Agora, utilizando um termo que foi lançado por nós há uns anos e que vai continuar a ser trabalhado, o que nós fazemos é a sua crioulização. Nós como que crioulizamos as obras originais, para torná-las mais nossas; a utilização da língua crioula tem uma força incrivel. Todos sabemos que o crioulo é a matriz da nossa cultura. Quando utilizamos o crioulo numa adaptação shakespeariana dá uma força cultural enorme que, se calhar, as manifestações folclóricas não dão, hoje em dia, em cima do palco. (Branco 2005: 28)

0 crioulo (excluimos esta ideia de matriz, pois o português também é a língua matriz do cabo-verdiano) tem uma força de oralidade superior ao português, e por isso talvez uma superior eficácia dramática. Para além disso, usando o crioulo, está-se imediatamente a coloca a aç̧ão em Cabo Verde. Uma interessante crioulização é a obra Á espera da chuva, de 2002, a partir do texto de Samuel Beckett, En attendant Godot. Foi feita uma adaptação do texto original ao contexto cabo-verdiano, apagando o carácter absurdo das personagens, do tempo e do espaço, e transformando-o num drama realista. João Branco considera que o texto de partida é apenas inspiração 


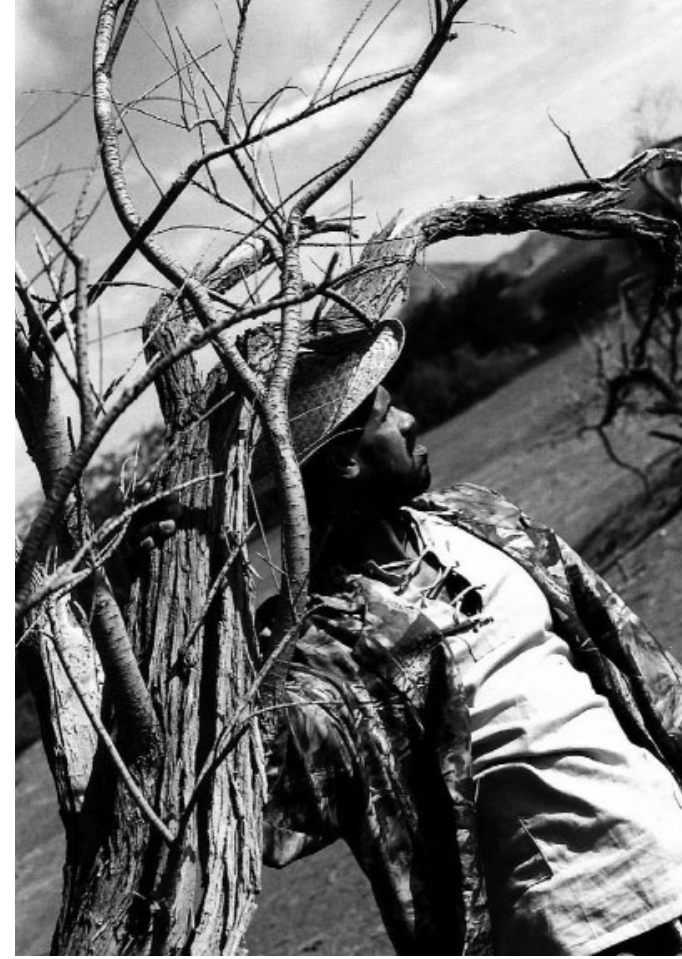

para a nova criação dramática: "Foi inspirado na obra de Beckett (...) A decisão foi muito intuitiva. Lembro-me que o quis fazer depois de ler uma notícia na primeira página do jornal A Semana, com o título "à espera das águas" e assim associei a Godot." ${ }^{4}$

Este texto fala sobre uma temática bastante marcante em Cabo Verde: a chuva, ou melhor, a sua ausência e a fatalidade de um povo que sofre esta condição. Esta agrura do clima sub-sahariano cria marcas identitárias muito fortes no homem cabo-verdiano: o sentimento de aceitação de um destino, de eterno retorno com a chuva e o ritual das sementeiras e, acima de tudo, o sentimento de fatalidade. "A imagem de duas pessoas num campo deserto, praticamente no meio do nada, à espera de algo ou alguém, sempre foi ligada a essa inevitabilidade que acompanha o mundo rural cabo-verdiano desde os tempos mais remotos, de semear e esperar por uma dádiva do céu" (2002: 11). A peça fala sobre a seca; a fábula consiste em dois agricultores que, em pleno campo de cultivo, esperam pela chuva que nunca vem, mas que vão imaginando o dia em que ela há-de vir. É claro neste texto que as personagens atribuem ao destino a razão das circunstâncias:

\footnotetext{
VLADIMIR: Por isso estamos aqui ainda.

ESTRAGON: Será teimosia?

VLADIMIR: Alguns chamam a isso destino.

ESTRAGON: Ou estupidez.

VLADIMIR: Destino. (p. 40)
}

Distante do texto de partida, não é do absurdo que aqui se fala, mas de um tema, realista e concreto, do povo cabo-verdiano: a espera da chuva para se iniciar a sementeira.

ESTRAGON: 0 que é que nós lhe pedimos, exactamente?

VLADIMIR: Oh... pedimos... nada de muito concreto...

ESTRAGON: Uma espécie de oração.

VLADIMIR: Exactamente.

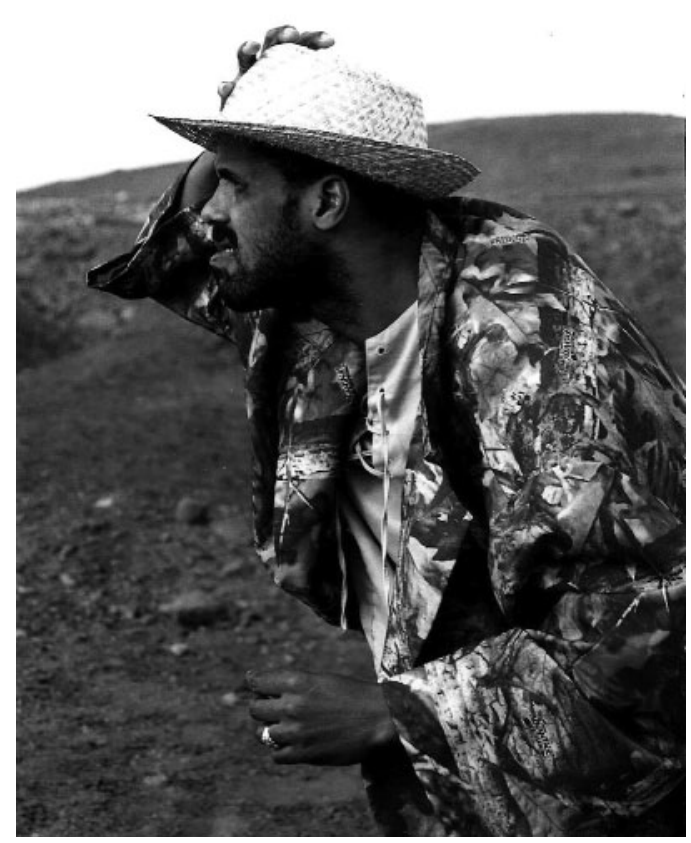

A espera da chuva escrita e enc. João Branco Grupo de Teatro do Centro Cultural Português do Mindelo, 2002 (Jorge Spenser), fot. João Branco.

\section{ESTRAGON: Uma súplica vaga}

\section{VLADIMIR: Mais ou menos.}

ESTRAGON: E o que é que ele dirá?

VLADIMIR: Que ela um dia há-de cair. (p. 12)

Neste excerto podemos apontar duas alterações significativas em relação ao texto de partida: a primeira diz respeito ao facto de as duas personagens, como percebemos pelo desenrolar da acção, fazerem pedidos, não a Godot, como as personagens de Beckett, mas a Deus. Temos, portanto, uma religiosidade associada a esta espera pela chuva, um recurso à divindade católica para que aja sobre o seu destino. 0 cabo-verdiano considera que a chuva cai, ou deixa de cair, segundo a vontade de Deus e aqui isso é realçado. A segunda alteração decorre do facto de Vladimir identificar a razão da espera - a chuva - e da "certeza" de que ela há-se cair, tornandose, assim, uma espera sem angústia. As personagens da crioulização são, muito concretamente, de Santiago e de Santo Antão, sabem porque estão ali, têm um passado e um futuro, o que claramente as distingue das personagens beckettianas. A relação entre as personagens, e seguindo o raciocínio de que são personagens que têm uma história, de que existem para além da cena, será uma relação de companheirismo (e aqui poderíamos facilmente pensar no djuntamon, a entreajuda comum dos cabo-verdianos, principalmente nas sementeiras) e não uma relação de dependência, como na obra de Beckett. Os dois estão juntos pela circunstância de aguardar a chuva para logo iniciarem a sementeira:

\section{ESTRAGON: Vamos embora.}

VLADIMIR: Para onde? (Pausa) Esta noite talvez a gente já possa semear. Vale a pena esperar, não te parece? (p. 5)

Foram retiradas da peça as cenas de Pozzo e Lucky, assim como a cena do rapaz, de modo a tornar a história 
$\dot{A}$ espera da chuva

escrita e enc. João Branco,

Grupo de Teatro do

Centro Cultural Português

do Mindelo, 2002

(Maria da Luz Faria), fot. João Branco.

mais real e concreta. Além disso Vladimir e Estragon aqu comunicam entre si, e o espaço em que se encontram é definido e concreto. A acção passa-se em S. Vicente, como vemos através de algumas réplicas:

VLADIMIR: Podiamos ter sido dos primeiros a deitar-nos do Monte Verde abaixo, os dois de mãos dadas. Nessa altura éramos pessoas respeitáveis. Agora, é tarde, é muito tarde. (p.4)

Esta referência ao Monte Verde (local na ilha de São Vicente), apesar de as personagens serem de Santo Antão e Santiago, apela a uma outra identificação, ao público sanvincentino, sendo, de resto, repetida a referência ao Mindelo (cidade de São Vicente).

Em relação ao tempo dramático, nesta crioulização encontramos um tempo linear, que se inicia por altura das sementeiras, ou seja, no período das chuvas, e que avança, dia a pós dia, até que a chuva caia e aí se encerre um ciclo. É um tempo ritualista, que tem um início e um fim, para depois retornar no ano seguinte, diferente, portanto, do que encontramos no texto beckettiano. $\mathrm{Na}$ versão de João Branco é inserida a questão da emigração, uma realidade muito presente na construção identitária do cabo-verdiano:

VLADIMIR: Estou contente por teres vindo. Julquei que te tinhas ido embora para sempre. Emigrado!

ESTRAGON: Também eu! (p. 3)

A linguagem da peça é quase na sua totalidade retirada do texto de Beckett, mas traduzida para o crioulo. É a oralidade que cria neste texto as diferentes enunciações, duas variantes do crioulo, como forma de identificar as personagens, como explica João Branco:

\footnotetext{
Acabamos por optar por uma terceira via que nos apareceu bem mais ajustada ao contexto que queriamos dar a esta peça, mas que nos colocou perante um desafio incomensurável: o homem fala crioulo de Santiago, a mulher ${ }^{5}$ responde com o crioulo de Santo Antão. (...) E desta forma, na nossa opinião, a peça ganha uma outra dimensão: em primeiro lugar porque fixa o contexto dos personagens num universo marcadamente rural, em segundo, porque dá uma maior amplitude ao drama nacional, que se repete todos os anos, materializado no facto de muitos e muitos camponeses caboverdianos, com enorme esforço, se dedicarem a uma sementeira, cujo resultado depende dos caprichos de uma natureza, que na maioria dos casos, se tem revelado madrasta. (2003: 276)
}

Para além das réplicas em crioulo, temos no texto a inserção da canção de embalar "Dia que tchuba bem" (p. 32), que uma das personagens vai intercalando na acção, assim reforçando a presença do contexto cabo-verdiano.

Mais um elemento que nos reenvia para o contexto cabo-verdiano. A partir de uma história sem fim aparente com uma redundância no tempo, no espaço, em

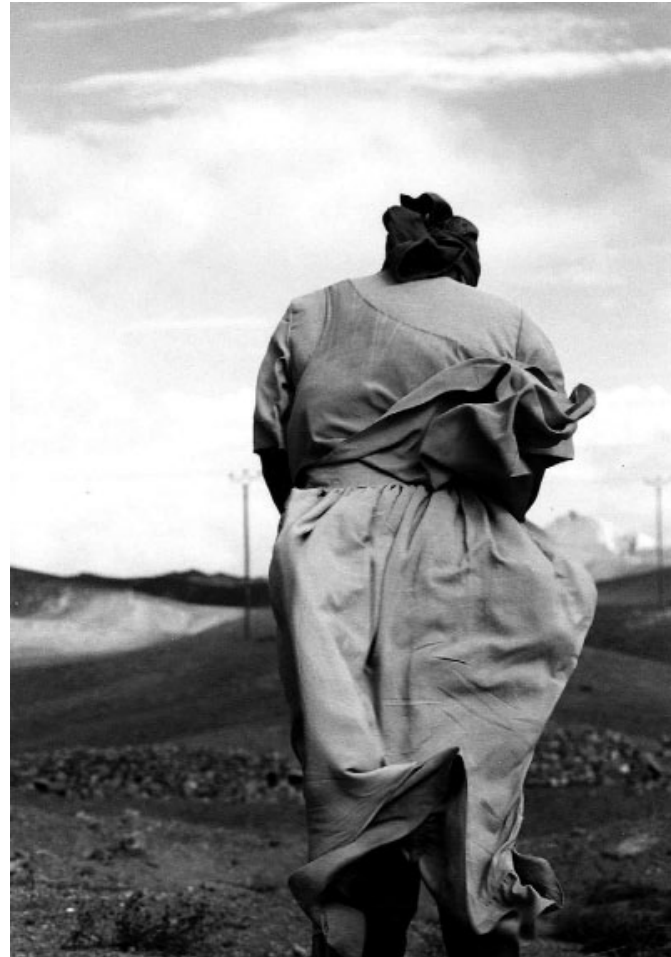

personagens que permanecem iguais do início ao fim e que assim permanecerão para sempre - pois não há um fim, não há uma esperança de desenlace - passamos a ter um texto que encerra, uma obra fechada, a resolução do conflito com a chuva que finalmente cai e que resolve toda a intriga.

Para além desta peça, o GTCCPM crioulizou obras de Lorca, Gil Vicente, Shakespeare, entre outros, mas, como escreve Germano Almeida, "As adaptações de obras literárias de grandes autores, que a humanidade conheceu, interpretadas à luz da realidade destas ilhas e utilizando como instrumento o crioulo, nada perdem da sua graça e magia, mas pelo contrário como que ganham um fôlego renovado" (1998: 13)

\section{Referências bibliográficas}

AALTONEN, (2007), Time-sharing on Stage: Drama Translation in Theatre and Society apud Bandin, Elena, "Translating English Renaissance Drama under Franco's Dictatorship: Stage Versions vs. Reading Editions", in BRILHANTE, M. J. / CARVALHO, Manuela, Teatro e Tradução - palcos de encontro, Porto, Campo das Letras.

ALMEIDA, Germano (1998), "O mundo do teatro em Cabo Verde", Mindelact - teatro em revista, n. ${ }^{\circ}$, Janeiro / Junho.

BASSNET, Susan (1991), Translations studies, London, Methuen.

BRANCO, João (2000), "Nação-Teatro: A afirmação de Cabo Verde nos palcos do mundo ou 0 porquê de um futuro risonho para as artes cénicas cabo-verdianas" Mindelact - Teatro em Revista $n$ n. 6, Janeiro I Junho.

--(2002), "À espera da chuva", Mindelact - Teatro em Revista, n. ${ }^{10}$, Janeiro/Junho.

-- (2003), Dez anos de teatro, Mindelo, Centro Cultural Português / Instituto Camões.

--(2004), Nação teatro, Mindelo, Instituto da Biblioteca e do Livro.

--(2005), "Crioulizamos as obras para torná-las mais nossas", Expresso das Ilhas, 9 de Março. 